\title{
PRAKTIK PENGISIAN SPT WAJIB PAJAK BADAN PADA SISWA-SISWI SMK KARYA BHAKTI KABUPATEN BREBES
}

\author{
Ririh Sri Harjanti ${ }^{1}$, Nurul Mahmudah ${ }^{2}$, Ghea Dwi Rahmadiane ${ }^{3}$, Musyafa alfarizi ${ }^{4}$, \\ Elisa Purwitasari ${ }^{5}$ \\ ${ }^{123}$ Program Studi DII Akuntansi Politeknik Harapan Bersama \\ Email: ririh.sriharjanti77@gmail.com
}

\begin{abstract}
Abstrak
Tujuan Pengabdian Masyarakat ini adalah untuk menambah wawasan dan kompetensi di bidang perpajakan khususnya dalam memahami perhitungan dan pengisian SPT Wajib Pajak Badan, khalayak kegiatan pengabdian masyarakat ini adalah siswa-siswi SMK Karya Bhakti Kabupaten Brebes. Adanya bentuk-bentuk pelatihan berupa pengisian Form SPT Wajib Pajak Badan untuk meningkatkan kompetensi perpajakan bagi siswa-siswi SMK Karya Bhakti Kabupaten Brebes, yang beralamat di Jalan Taman Siswa, Saditan, Kecamatan Brebes Kabupaten Brebes Jawa Tengah. Jarak tempuh kampus dengan khalayak sasaran kurang lebih $5 \mathrm{~km}$ yang dapat ditempuh menggunakan trasportasi mobil. Metode atau cara yang digunakan dalam Kegiatan Pengabdian pada Masyarakat ini adalah pertama dengan menggunakan metode survei, dimana tim melakukan survei langsung ke lokasi untuk pengumpulan data awal. Selain melakukan survei, tim juga melakukan observasi dan wawancara. Observasi dan wawancara ini dilakukan pada tahap awal dalam rangka mengumpulkan data dan mencari permasalahan sebelum memutuskan kegiatan pengabdian seperti apa yang sesuai dengan khalayak sasaran. Wawancara dilakukan dengan pihak guru dari SMK Karya Bhakti Kabupaten Brebes.
\end{abstract}

Kata Kunci :Pajak, SPT, Wajib Pajak, Badan

\section{PENDAHULUAN}

Pajak secara bebas dapat dikatakan sebagai suatu kewajiban warga negara berupa pengabdian serta peran aktif warga negara dan anggota masyarakat untuk membiayai berbagai keperluan negara dalam Pembangunan Nasional, tanpa adanya imbalan secara langsung yang pelaksanaannya diatur dalam Undang-Undang Perpajakan untuk tujuan kesejahteraan bangsa dan negara. Dengan semakin berkembangnya kondisi usaha dan bisnis baik ditingkat nasional maupun internasional, maka penghasilan yang diterima wajib pajak badan dalam negeri juga meningkat. Badan atau perusahaan merupakan subjek pajak dalam negeri dimana wajib pajak badan ini merupakan penyumbang bagi penerimaan negara dari sektor pajak yaitu pajak penghasilan badan.

Pajak adalah pungutan wajib yang dibayar rakyat untuk negara dan akan digunakan untuk kepentingan pemerintah dan masyarakat umum. Rakyat yang membayar pajak tidak akan merasakan manfaat dari pajak secara langsung, karena pajak digunakan untuk kepentingan umum, bukan untuk kepentingan pribadi. Pajak merupakan salah satu sumber dana pemerintah untuk melakukan pembangunan, baik pemerintah pusat maupun pemerintah daerah. Pemungutan pajak dapat dipaksakan karena dilaksanakan berdasarkan undangundang.Dalam hal menjalankan usaha, suatu badan atau perusahaan harus membuat pembukuan untuk menunjang kegiatan usahanya. Sama halnya dalam perpajakan, pembukuan juga wajib dibuat oleh wajib pajak yang berbentuk badan untuk mempermudah menghitung 
pajaknya. Dalam makalah ini akan dibahas mengenai wajib pajak badan, kewajiban dan hak wajib pajak badan dalam perpajakan dan cara penghitungan pajak dari wajib pajak badan.

Penerimaan pajak saat ini kenyataannya belum sesuai dengan harapan pemerintah, disebabkan karena Wajib Pajak dalam membayar kewajiban pajaknya tidak tepat waktu dan bahkan tidak sedikit pengusaha yang tidak melaporkan usahanya sehingga penerimaan pajak tidak dapat maksimal. Dalam kegiatan pengabdian masyarakat ini di fokuskan dalam bentuk peningkatan kemampuan perpajakan SPT Bagi Wajib Pajak Badan.Pelaksanaan kegiatan pengabdian masyarakat ini yang kaitannya berupa pelatihan, hal ini agar siswa-siwi mampu meningkatan kemampuan perpajakan dalam menghitung dan menyampaikan SPT Bagi Wajib Pajak Badan sebagai langkah kedepannya untuk dapat diterapkan dalam kehidupan nyata dan bekal dalam melanjutkan pada jenjang perguruan tinggi.

\section{METODE}

Adanya pemaparan mengenai pengetahuan perpajakan dan pengisian SPT Wajib Pajak Badan khususnya bagi siswa-siswi SMK Karya Bhakti Kabupaten Brebes.Adanya bentuk-bentuk pelatihan berupa pengisian Form SPT Wajib Pajak Badan untuk meningkatkan kompetensi perpajakan bagi siswa-siswi SMK Karya Bhakti Kabupaten Brebes, yang beralamat di Jalan Taman Siswa, Saditan, Kecamatan Brebes Kabupaten Brebes Jawa Tengah. Jarak tempuh kampus dengan khalayak sasaran kurang lebih $5 \mathrm{~km}$ yang dapat ditempuh menggunakan trasportasi mobil.

Metode atau cara yang digunakan dalam Kegiatan Pengabdian pada Masyarakat ini adalah pertama dengan menggunakan metode survei, dimana tim melakukan survei langsung ke lokasi untuk pengumpulan data awal. Selain melakukan survei, tim juga melakukan observasi dan wawancara. Observasi dan wawancara ini dilakukan pada tahap awal dalam rangka mengumpulkan data dan mencari permasalahan sebelum memutuskan kegiatan pengabdian seperti apa yang sesuai dengan khalayak sasaran. Wawancara dilakukan dengan pihak guru dari SMK Karya Bhakti Kabupaten Brebes.

Berikut adalah tahapan-tahapan yang dilakukan dalam melaksanakan Kegiatan Pengabdian Kepada Masyarakat:

1) Melakukan studi literatur mengenai Peraturan perpajakan terbaru tentang SPT Wajib Pajak Badan serta perlu dilakukannya usaha untuk meningkatkan Kompetensi tersebut dalam bentuk kegiatan Pengabdian Kepada Masyarakat.

2) Pemilihan khalayak sasaran SMK Karya Bhakti Brebes karena sekolah ini merupakan salah satu sekolah swata favorit di kabupaten brebes sehingga sekolah ini selalu menjadi percontohan bagi sekolah swasta lain yang berada di Brebes.

3) Dilakukan observasi awal ke lokasi SMK Karya Bhakti Brebes. Obervasi ini dilakukan untuk mengumpulkan data awal mengenai temuan permasalahan yang dihadapi. Selain itu juga dilakukan wawancara dengan pihak-pihak terkait sehubungan dengan temuan masalah dan keinginan tim untuk melakukan kegiatan Pengabdian Kepada Masyarakat di lokasi tersebut.

4) Menyusun proposal kegiatan Pengabdian Kepada Masyarakat.

5) Pelaksaaan kegiatan pengabdian kepada masyarakat di SMK Karya Bhakti Kabupaten Brebes, dengan tema "Praktik Pengisian Spt Wajib Pajak Badan Pada Siswa-Siswi Smk Karya Bhakti Kabupaten Brebes". 


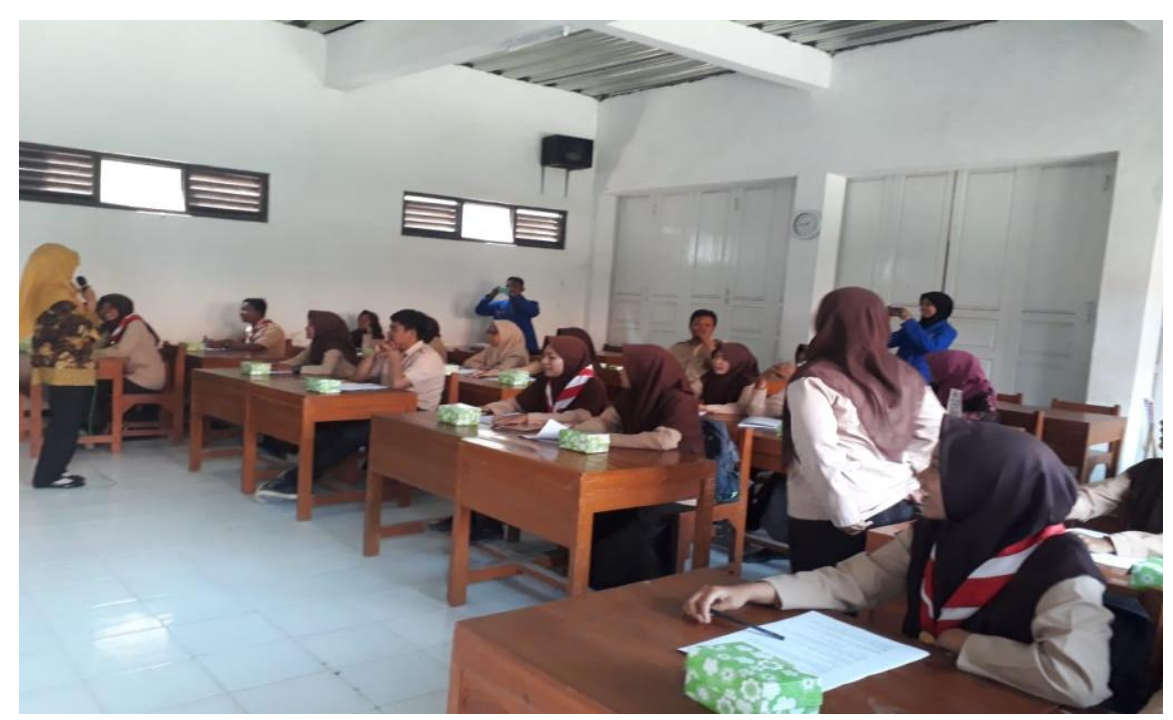

Gambar 1: Pemaparan Materi Pengisian SPT Wajib Pajak Badan Kepada Siswa-siswi SMK Karya Bhakti Kabupaten Brebes.

\section{Tnjauan Pustaka}

2.1. Akuntansi Pajak

Menurut Muljono (2009), akuntansi pajak adalah bidang akuntansi yang berkaitan denganperhitungan perpajakan, yang mengacu pada peraturan, undang-undang, dan aturan pelaksanaanperpajakan. Prinsip-prinsip yang diakui dalam akuntansi perpajakan meliputi ${ }^{1}$ :

1. Kesatuan akuntansi

2. Kesinambungan

3. Harta pertukaran yang objektif

4. Konsistensi

5. Konservatif

\subsection{Definisi Pajak}

Menurut Soemitro dalam Mardiasmo (2011) Pajak adalah iuran rakyat kepada kas Negara berdasarkan Undang-Undang (yang dapat dipaksakan) dengan tiada mendapat jasa timbal (kontra prestasi) yang langsung dapat ditunjukkan dan yang digunakan untuk membayar pengeluaran umum ${ }^{2}$. Menurut Rahayu (2010) menjelaskan bahwa pengertian fungsi dalam pajak adalah sebagai kegunaansuatu hal. maka fungsi pajak adalah kegunaan pokok, mafaat pokok pajak. Sebagai alat untukmenentukan politik perekonomian, pajak memiliki kegunaan dan manfaat pokok dalammeningkatkan kesejahteraan umum. Dengan pajak sebagai salah satu pos penerimaan negaradiharapkan banyak membangun dapat dilaksanakan sesuai dengan tujuan negara ${ }^{3}$.

Wajib Pajak badan adalah badan seperti yang dimaksud pada undang-undang KUP, meliputi membayar pajak, pemotong pajak, dan pemungut pajak, yang mempunyai hak dan kewajiban perpajakan sesuai dengan ketentuan peraturan perundang-undangan perpajakan atau memiliki kewajiban subjektif dan kewajiban objektif serta telah mendaftarkan diri untuk memperoleh Nomor Pokok Wajib Pajak.

\subsection{Pajak Penghasilan Badan Pasal 25/26}

Menurut Dianadan Lilis(2009) Pajak Penghasilan adalah sekumpulan orang dan atau modal yang merupakan kesatuan baik yang melakukan usaha maupun yang tidak melakukan usaha. Badan adalah perseroan terbatas, perseroan komenditer, dan perseroan lainnya, Badan Usaha Milik Negara atau badan usaha milik daerah dengan nama dan bentuk apa pun, firma, kongsi, koperasi, dana pensiun, persekutuan ${ }^{4}$.Pajak Penghasilan badan adalah pajak yang terutang oleh subjek pajak berupa badan atas penghasilan yang diperoleh atau diterimanya dalam tahun takwim atau tahun pajak.Menurut Purwono (2010) Wajib Pajak adalah orang pribadi atau badan, 
meliputi pembayar pajak, pemotong pajak, dan pemungut pajak, yang mempunyai hak dan kewajiban perpajakan sesuai dengan ketentuan peraturan perundangundangan perpajakan ${ }^{5}$.

\section{HASIL DAN PEMBAHASAN}

Kegiatan Pengabdian Masyarat ini dilaksanakan pada SMK Karya Bhakti Kabupaten Brebes. Kegiatan pengabdian masyarakat kali ini merupakan lanjutan dari kegiatan pengabdian masyarakat pada tahun sebelumnya yang diaplikasikan dalam bentuk pelatihan mengenai Perpajakan tentang Pengisian SPT Wajib Pajak Badan Pada Siswa-Siswi SMK Karya Bhakti Kabupaten Brebes. Pelatihan ini di hadiri oleh kurang lebih sekitar 30 orang. Kegiatan ini disambut positif oleh pihak Sekolah SMK Karya Bhakti Kabupaten Brebes yang bergabung dalam kegiatan pelatihan tersebut, mengapa demikian? Karena pada dasarnya para siswa-siswi sangat membutuhkan pelatihan dan sosialisasi mengenai perpajakan khususnya tentang pengisian SPT WP Badan, hal ini didasasri oleh banyaknya peraturanperaturan terbaru tentang pajak yang harus diketahui oleh para siswa-siswi. Dalam hal ini kami selaku tim pengabdian kepada masyarakat berharap dengan adanya kegiatan pelatihan mengenai perpajakan pengisian SPT WP Badan ini mampu memberikan manfaat dan pemahaman yang sangat mendalam khususnya mengenai Pengisian SPT WP Badan agar lebih siap dalam menghadapi issue tentang pajak. Kegiatan pengabdian masyaraka ini banyak sekali siswa-siswi yang kreatif memberikan pertanyaan-pertanyaan serta harapan untuk diadakannya tindak lanjut dari kegiatan pelatihan perpajakan berupa bimbingan teknis yang lebih mendalam tentang pelatihan perpajakannya.

Adapun beberapa agenda yang direncanakan dalam kegiatan pengabdian masyarakat diantaranya:

\begin{tabular}{|l|l|l|}
\hline No. & Acara & Keterangan \\
\hline 1. & Pembukaan Oleh MC & $\begin{array}{l}\text { Elisa Purwitasari, SE, M.Acc, Ak } \\
\text { (Tim PKM) }\end{array}$ \\
\hline 2. & Sambutan Pihak SMK Karya Bhakti & Dra. Ibu Tafridah \\
\hline 3. & Sambutan Tim Pelaksana PKM & $\begin{array}{l}\text { Nurul Mahmudah, SE, M.Si, Ak (Tim } \\
\text { PKM) }\end{array}$ \\
\hline 4. & Materi Pelatihan Pengisian SPT OP & $\begin{array}{l}\text { Ririh Sri Harjanti, SE, M.Si (Tim } \\
\text { PKM) }\end{array}$ \\
\hline 5. & Dokumentasi & $\begin{array}{l}\text { Ghea Dwi Rahmadiane, SE, M.Si } \\
(\text { Tim PKM) }\end{array}$ \\
\hline 6. & Penutup oleh MC & MC (Tim PKM) \\
\hline
\end{tabular}

adapun materi yang disampaikan dalam kegiatan pelatihan pengabdian kepada masyarakat yaitu:

\section{A.KETENTUAN PERHITUNGAN DAN PELAPORAN PPH BADAN \\ 1. Peredaran Bruto $(\mathrm{PB})<$ atau $=\mathrm{Rp} 4,8$ Milyar setahun}

Maka menggunakan ketentuan menurut PP No 46 tahun 2013 (berlakumulaitahun $2013 \mathrm{~s} / \mathrm{d}$ Juni 2018)

$\mathrm{PPh}$ Badan Terutang $=1 \% \mathrm{X}$ Omzet per bulan

Setelahada PP No tahun 2018 (yang berlakumulai 1 JULI 2018 S/D SEKARANG)

$\mathrm{PPh}$ Badan Terutang $=1 / 5 \% \mathrm{X}$ Omzet per bulan

Kasus1 :

PT Andika pada tahun 2017 mempunyai Peredaran Bruto (PB) Rp 3.650.750.000,- maka ketentuan PPh Badan terutang harus memenuhi ketentuan PP yang baru. Apabila pada bulan Juli 2018 PT Andika mempunyai PB sebesar Rp 375.685.000,- . Hitunglah PPh Terutang pada bulan Juli 2018 ?

Jawab :

PPhbulanJuli 2018 yang harusdibayar

$=1 / 5 \%$ x Rp375.685.000,-

$=\operatorname{Rp} 1.878 .425$ 


\section{Peredaran Bruto > Rp 50 Milyar setahun}

Maka menggunakan ketentuan UU No 36 tahun 2008 ( pasal 17 ayat 1b)

$\mathrm{PPh}$ Terutang $=$ Tarif $\mathrm{x}$ PKP

\section{Kasus2 :}

$$
=25 \% \times \text { Laba sebelum pajak }
$$

Selama tahun 2016 diketahui PT Ceria mempumyai PB sebesar Rp 67.850.000.000,dengan penghasilan netto fiskal atau Penghasilan Kena Pajak pada tahun 2017 sebesar Rp 15.750.500.000. Hitunglah PPh terutang PT Ceria untuk tahun pajak 2017 ?

Jawab :

PPh 21 tahun 2017

$$
\begin{aligned}
& =\text { TARIF X PKP } \\
& =25 \% \text { X Rp 15.750.500.000,- } \\
& =\operatorname{Rp~3.937.625.000,-~}
\end{aligned}
$$

\section{Peredaran Bruto > Rp 4,8 Milyar s/d 50 Milyar setahun}

Maka menggunakan ketentuan UU No 36 tahun 2008 ( pasal 17 ayat 1b dan pasal 31E)

Contoh Soal :

PT "Beres Bro" pada tahun 2015 mempunyai PB sebesar Rp 4.975.500.000,-

Diketahui PT "Beres Bro" pada tahun 2016 mempunyai PB atauomzetsebesar Rp 5.000.000.000,- dengan LabaNettoFiskal sebesar Rp 304.000.000,- . Hitung PPh terutang pada PT "Beres Bro" tahun 2016 ?

Berikut data-data berkaitan dengan PT "Beres Bro" pada tahun 2016.

\section{B. REKONSILIASI FISKAL}

Contoh Soal:

PT Maju Jaya pada tahun 2016 mempumyai daftar format Rekonsiliasi Fiskal sbb :

Tabel 1: Format Rekonsiliasi Fiskal

\begin{tabular}{|l|l|l|l|l|}
\hline \multirow{2}{*}{ Akun } & Komersial & Rekonsiliasi Fiskal & \multirow{2}{*}{ Fiskal (Rp) } \\
\hline & $\mathbf{( R p )}$ & Positif (Rp) & Negatif (Rp) & \\
\hline Peredaran Usaha (Tidak & 5.200 .000 .000 & & & \\
\hline Biaya-biaya : & & & & \\
\hline 1. Biaya gaji & 990.000 .000 & & & \\
\hline 2. Biaya Iklan & 125.000 .000 & & & \\
\hline 3. Biaya sewa gedung Kantor & 225.000 .000 & & & \\
\hline $\begin{array}{l}\text { 4. Biaya Piknik Keluarga } \\
\text { Direktur }\end{array}$ & 100.000 .000 & & & \\
\hline 5. Biaya Pulsa & 10.000 .000 & & & \\
\hline 6. Biaya PBB & 50.000 .000 & & & \\
\hline 7. Biaya Deductible Lainnya & 700.000 .000 & & & \\
\hline 8. Biaya NonDeductibleLainnya & 350.000 .000 & & & \\
\hline Jumlah Biaya & 2.550 .000 .000 & & & \\
\hline Laba Usaha & 2.650 .000 .000 & & & \\
\hline Ph Bunga Deposito (Final) & 40.000 .000 & & & \\
\hline Laba Netto & 2.690 .000 .000 & & & \\
\hline
\end{tabular}




\section{KESIMPULAN}

Kegiatan pengabdian kepada masyarakat dengan metode ceramah dan pelatihan mengenai Praktik Pengisian Spt Wajib Pajak Badan Pada Siswa-Siswi Smk Karya Bhakti Kabupaten Brebes. Kegiatan ini berhasil membuat para peserta menjadi sadar akan pentingnya kemampuan dalam mengisi SPT Wajib Pajak Badan. Kegiatan ini menjadi sarana para peserta untuk belajar dan menambah wawasan serta pengetahuan, khususnya dalam bidang perpajakan. Selain itu implikasi yang dihasilkan dalam Pengabdian Kepada Masyarakat ini adalah siswa-siswi dapat ikut mempraktekkan cara mengisi SPT Wajib Pajak Badan. Praktek yang dilakukan adalah mengisi Form SPT ajib Pajak Badan dan menghitungnya. Kegiatan ini menjadi sebuah jembatan penghubung untuk terjalinnya kerjasama bagi pihak tim pengabdian Prodi Akuntansi Politeknik Harapan Bersama dan sekolah SMK Karya Bhakti Kbupaten Brebes, guna mengadakan kegiatan pengabdian lainnya. Selain itu, kegiatan ini berhasil memperkenalkan eksistensi Program Studi DIII Akuntansi Politeknik Harapan Bersama.

\section{SARAN}

Saran untuk kegiatan selanjutnya diharapkan materi yang disampaikan lebih aplikasif sehingga dibutuhkan alat peraga seperti komputer untuk langsung dapat menghitung dan mengisi SPT secara Online. Objek pengabdian kepada masyarakt juga diharapkan diperluas dan ada tindak lanjut sehingga tujuan PKM dapat tersampaikan dengan baik.

\section{UCAPAN TERIMAKSIH}

Tim pengabdian dari Program Studi DIII Akuntansi Politeknik Harapan Bersama mengucapkan terima kasih yang sebesar-besarnya kepada seluruh pihak yang telah membantu dan mendukung terlaksananya kegiatan pengabdian ini. Secara khusus, ucapan terima kasih diberikan kepada SMK Karya Bhakti Kabupaten Brebes yang telah menerima dan bersedia bekerjasama dengan tim. Kemudian kepada institusi dan P3M Politeknik Harapan Bersama yang menjadi penyedia dana acara ini.

\section{DAFTAR PUSTAKA}

[1] Muljono Djoko, 2009. Akuntansi Perpajakan, Edisi Revisi 2009. Andi. Jogjakarta

[2] Mardiasmo. 2011. Perpajakan Edisi Revisi 2011. Yogyakarta: Andi.

[3] Rahayu, Siti Kurnia. 2010. Perpajakan Indonesia. Yogyakarta : Graha Pustaka

[4] Diana, Anastasia dan Lilis Setiawati. 2009. Perpajakan Indonesia (Konsep, Aplikasi, dan Penuntun Praktis). Yogyakarta: Andi.

[5] Purwono, Herry. 2010. Dasar-dasar Perpajakan dan Akuntansi Perpajakan. Jakarta : Erlangga. 